\title{
I Algunas consideraciones en torno al aná- lisis de los manifiestos fundacionales de la Unión Democrática y el Partido Peronista en La Pampa (1945-1947)
}

\author{
Jorge Etchenique ${ }^{2}$ \\ Vanina Hauser ${ }^{3}$
}

\section{Consideraciones preliminares}

Finalizada la década de 1930, en el marco de una crisis del consenso liberal y ante la demanda por una redefinición de las funciones del Estado, el golpe militar del 4 de junio de 1943 inauguró un nuevo periodo de la historia argentina al preparar el camino para el surgimiento del peronismo (Plotkin 1993, Romero 1994).

Frente a este movimiento, que ya hacia 1945 se hallaba afirmado en sus bases, la oposición estuvo representada por otra coalición de grupos políticos reunidos en la Unión Democrática Nacional ${ }^{4}$. Esa disputa, que marcó el periodo fundacional del peronismo en Argentina, se reflejó en La Pampa pese a su situación marginal respecto de la política nacional.

En efecto, la condición de exclusión política en que se hallaban los

1 - Una versión preliminar de este trabajo fue presentada en las Decimosextas Jornadas de Investigación de la Facultad de Ciencias Humanas de la Universidad Nacional de La Pampa, 10-12 de septiembre de 2003. Agradecemos las lecturas y sugerencias de los profesores Ana Rodríguez y Jorge Saab. 2- Sociólogo, Departamento de Investigaciones Culturales (Subsecretaría de Cultura de La Pampa). IESH, Universidad Nacional de La Pampa. E-mail etchemar@cpenet.com.ar

3- Estudiante de la carrera de Historia, IESH, Universidad Nacional de La Pampa. E-mail vaninahauser@yahoo.com.ar

4- La Unión Democrática fue una alianza conformada por los partidos Radical, Socialista, Demócrata Progresista y Comunista, con el apoyo de una parte de la ex Concordancia, que confrontó con el peronismo en las elecciones presidenciales del 24 de febrero de 1946. En dichos comicios, la fórmula Perón-Quijano por el Partido Laborista-UCR Junta Renovadora triunfó frente a los candidatos de la coalición opositora Tamborini-Mosca. 
habitantes de los Territorios Nacionales ${ }^{5}$-en tanto entidades jurídicas sin autonomía y en directa dependencia del poder central- no impidió que desde muy temprano se generaran espacios para el debate sobre lo público ${ }^{6}$. Por el contrario, se observa en este caso una fuerte expresión de gestos de adhesión u oposición hacia ambas agrupaciones políticas que contrasta con lo esperado, si consideramos que se trataba de una sociedad que desde sus inicios carecía de derechos electorales y donde el ejercicio de la representación política quedaba acotado a la esfera municipal.

Pese a estas limitaciones, desde el mismo momento de constitución de la sociedad civil en el Territorio, los actores desarrollaron variadas formas de mediación entre las cuestiones políticas locales y el poder central que superaron el ejercicio formal de la ciudadanía. ${ }^{7}$ El clima de agitación política percibido en el seno de ciertos grupos de la sociedad pampeana en vísperas de los comicios presidenciales de febrero de 1946, revela una clara intención de formar parte de la dinámica política nacional.

Nuestro propósito en este trabajo es doble. En primer lugar, nos proponemos dar a conocer algunos aspectos acerca de la constitución y propuesta política del Partido Peronista y de la Unión Democrática durante sus pri-

5- A través de la ley $\mathrm{N}^{\circ} 1532$ (1884) se crearon nueve Territorios Nacionales: Misiones, Formosa, Chaco, la Pampa, Neuquén, Río Negro, Chubut, Santa Cruz y Tierra del Fuego. En el año 1900, mediante la ley $\mathrm{N}^{\circ} 3906$ se creó el Territorio Nacional de Los Andes.

Además de fijar los límites, la ley orgánica de Territorios Nacionales previó un ordenamiento políticoinstitucional para los mismos que los situaba en una cuasi plena dependencia del poder central -tanto administrativa como presupuestaria-, más precisamente del Ministerio del Interior.

El Poder Ejecutivo Nacional, con acuerdo del Senado, era quien nombraba al Gobernador, a los empleados de la Gobernación y al Juez Letrado Nacional. El Gobernador designaba a los jueces de paz y comisiones de fomento en distritos con menos de mil habitantes y a los comisarios de policía. En el caso de localidades que superaran los mil habitantes, podían constituirse concejos municipales electos. Se establecía la provincialización para los territorios con más de sesenta mil habitantes y, las poblaciones que superaran los treinta mil tenían derecho a constituir sus propias legislaturas. Pese a cumplir con los requisitos establecidos en la normativa, nunca se constituyeron las legislaturas ni los territorios fueron provincializados oportunamente.

6- Los pobladores de los territorios nacionales desarrollaron variadas modalidades de intervención en el ámbito público a través de las cuales canalizaron sus demandas, construyeron poder y definieron sus propias representaciones acerca de la política: denuncias judiciales, petitorios y presentaciones ante los poderes Ejecutivo y Legislativo, uso de la prensa escrita, manifestaciones públicas, gestiones ante diputados nacionales para la presentación de proyectos provincializadores, etc.

7- Entre las interpretaciones acerca de las formas o vías de representación que hacen a la construcción de la ciudadanía seguimos en este artículo aquella que excede a la incidencia de las prácticas electorales y que tiene en cuenta otros mecanismos de representación elaborados por los actores para plantear las relaciones entre la sociedad civil y el Estado (Sábato 1994). 
meros años en La Pampa ${ }^{8}$. En segundo lugar, intentaremos exponer y poner en discusión algunas de nuestras apreciaciones sobre la construcción de la ciudadanía en este espacio, teniendo en cuenta el efectivo impacto de ambos discursos en la realidad socio-política territoriana.

Se han rescatado para el análisis los respectivos manifiestos fundacionales -de la Junta Pro Unión Democrática (1945) y de la Junta Territorial del Partido Peronista (1947)-, procurando establecer algunas diferencias y similitudes entre ambos proyectos políticos a partir de ciertos tópicos presentes en los mismos. En este sentido, las consecuencias del golpe militar del 4 de junio de 1943 en La Pampa, la presencia de temas económicos y sociales como la comercialización regulada o no de los productos del agro y la situación de la clase trabajadora, las posturas autonomistas así como la extensión de los derechos políticos a las mujeres, constituyen algunos de los ejes en torno a los cuales se organiza el trabajo.

Con respecto a la segunda cuestión planteada, uno de los rasgos salientes de la coyuntura en que se gestó el movimiento peronista fue el intenso debate cívico iniciado antes de 1943 pero agudizado tras el golpe militar (Altamirano 2003). En el balance sobre el estado de las instituciones, los habitantes de los Territorios Nacionales insertaron sus antiguas demandas por el pleno reconocimiento de sus derechos políticos. Esos reclamos estuvieron presentes en los discursos de ambos movimientos en La Pampa. La importancia asignada desde la Unión Democrática al plano de lo político-institucional, y por otra parte, el énfasis del documento peronista en cuestiones de tipo económico-social, orientaron nuestras reflexiones hacia la problemática de la ciudadanía.

Desde la historiografía nacional los aportes sobre el tema no han contemplado ni mucho menos profundizado en la configuración específica de la ciudadanía en los Territorios Nacionales. La coexistencia por más de sesenta años en un mismo Estado de dos tendencias de gobierno diferentes -una federal y otra fuertemente centralista/centralizadora- y su implicancia en el tema de la soberanía, no ha recibido el suficiente tratamiento por parte de los in-

8- Desde hace algunos años se han dado a conocer diversas producciones por parte de investigadores de la Universidad Nacional de La Pampa que abordan el peronismo desde una perspectiva de género realizando aportes vinculados a cuestiones tales como maternidad, educación, salud, deporte, entre otros. Para la problemática de la construcción de la ciudadanía y la incorporación de las mujeres a la política institucional. Véase Zink 2000 y Zink y Di Liscia 2003. 
vestigadores, excepto algunas producciones realizadas en los últimos años ${ }^{9}$.

A esta altura, ha quedado claro que el clásico enfoque de Marshall sobre los procesos de construcción de la ciudadanía, no ha agotado ni clarificado en forma aceptable el análisis de esta temática tanto para estos espacios como para el resto del país. El matiz evolutivo y unilineal que lo caracteriza, sumado a la tendencia ineludible de muchos estudios de identificar en forma exclusiva ciudadanía política con elegir y ser elegido, han creado límites que aún hoy obturan el camino hacia una amplia y cabal comprensión de las formas y vías de constitución de la ciudadanía (Lobato 1997; Romero y Gutiérrez 1995).

No existen dudas de que el proceso histórico de construcción de la ciudadanía en La Pampa -como en el resto de los Territorios Nacionales-, adquirió ribetes singulares que lo distinguen del experimentado en el resto del espacio nacional. La tarea que se presenta ahora, es realizar un aporte más sobre este problema, abordándolo desde una perspectiva que definitivamente se aparte de las generalizaciones, que contemple las particularidades de los procesos aquí desarrollados y que a su vez nos permita volver a mirar nuestra historia nacional desde una posición más plural.

Pese a considerar que la ciudadanía política no se agota en el plano electoral, veremos que si seguimos la secuencia de adquisición de derechos propuesta por Marshall, en el Territorio Nacional de La Pampa el acceso a los derechos sociales -en su mayoría conquistas sociales promovidas por el peronismo- fue un logro previo a la obtención de los derechos políticos. Estos llegarían más tarde, cuando se accediera a la condición de provincia.

\section{La Unión Democrática en La Pampa}

¿Se reflejó en La Pampa la movilización de las columnas obreras a Plaza de Mayo el 17 de octubre de 1945? Sí, pero con un eco limitado a la ciudad de General Pico a raíz de la escasa inserción organizada que tenía aún el laborismo en el Territorio y a la ausencia de concentraciones obreras importantes como la ferroviaria en esa ciudad (Etchenique 2003).

En el ámbito nacional, los trabajadores nucleados en la Unión Ferro-

9- Sin ser exhaustivos, pueden mencionarse entre los trabajos más recientes, para La Pampa: Zink 2000; Diez, Hauser y Dietrich 2001; Etchenique 2001 y 2003. Para el Chaco: Maeder 2002 y Leoni 2002. Para Neuquén: Arias Bucciarelli 2003; Favaro y Arias Bucciarelli 2002. Para Río Negro: Ruffini 2003, entre otros. 
viaria fueron quienes prestaron uno de los apoyos más decisivos a Juan D. Perón desde su gestión en la Secretaría de Trabajo y Previsión (Gerchunoff y Llach1998). En el caso de La Pampa, el proceso siguió similares carriles. No obstante, así como el peronismo pampeano germinó desde los talleres ferroviarios de General Pico, el mismo escenario fue el embrión de la Unión Democrática. Ferroviarios radicales y socialistas que no habían mudado de adhesión u opositores en general a la política oficial, formaron el Comando Ferroviario de la Unión Democrática en un acto que tuvo lugar en la biblioteca Juan B. Justo el 22 de noviembre de $1945^{10}$.

De los partidos que integraron la Unión Democrática en La Pampa, el Partido Radical se remontaba a 1916. Junto a su aliado Socialista, fundado tres años antes, habían monopolizado la vida electoral hasta el momento. El Partido Comunista se hallaba constituido hacia 1922 y las fuerzas conservadoras, una parte de las cuales confluyeron en esta alianza opositora, habían tenido experiencias partidarias de efímera duración en el Territorio. Como agrupamiento, la Unión Democrática estuvo precedida en La Pampa por Acción Argentina, una organización que en Santa Rosa tuvo su lanzamiento en 1940 y que sucedió al Frente Antifascista de años anteriores ${ }^{11}$.

A posteriori de la primera experiencia organizativa en General Pico, un conjunto de fuerzas adversas al peronismo convocó a una asamblea en el Teatro Español de Santa Rosa el 8 de diciembre de 1945, el mismo día en que la Unión Democrática realizaba su primer mitín en Plaza Congreso con un saldo de varias víctimas, y cuando su fórmula José Tamborini-Enrique Mosca tenía tres semanas de vida. La asamblea designó una junta promotora cuya comisión ejecutiva integraron el abogado socialista Alfonso Corona Martínez, Juan B. Achiary, Víctor Arriaga, Guillermo Etcheverry y Santiago Mar$z^{12}$, quienes elaboraron el manifiesto inaugural de la Unión Democrática en

10- Calificándose a sí mismos como "anticolaboracionistas", estos ferroviarios poco tiempo después editaron el periódico Unidad, hecho indicativo de la agitación que reinaba en ese sector obrero en torno a la aprobación o reprobación del peronismo y también de la importancia de los ferroviarios en el termómetro político de General Pico desde las épicas jornadas de 1917.

11- Con el nombre de Acción Argentina, esta organización sucedánea del Frente Popular Antifascista de años anteriores, tuvo su versión santarroseña desde julio de 1940 con Alfonso Corona Martínez, Joaquín Fernández Herrero y Octavio Córdoba, entre otros, quienes organizaron un acto en el Base Club en octubre del mismo año.

12- En la convocatoria a la asamblea también figuraron los nombres de Bernardino Aguirre, Leopoldo Alcayaga, Pedro Paghouapé, José Camacho, Raúl D’Atri, Domingo Gentile, José D. Nale, Miguel Angel Mariani y Juan C. Brito. 
La Pampa. En dicho documento el peronismo era concebido como una seria amenaza para las instituciones demoliberales por su tendencia básicamente fascista y entonces el eje discursivo se centraba en ...el restablecimiento de la forma de gobierno representativa, republicana y federal de la Constitución.

En función de este esquema, la Juventud del Partido Socialista de Santa Rosa alertó en noviembre de 1945 que se encontraba en pleno desarrollo un movimiento "que se parece, como una gota de agua a otra gota de agua, al fascismo italiano"13.

Por la prioridad absoluta otorgada a las "instituciones", se observa la ausencia de enunciados dedicados a contrarrestar el punto de mayor atracción masiva del peronismo: la protección social, la extensión de la categoría "trabajador formal" y el vínculo entre ambas cuestiones.

\section{Del laborismo al peronismo pampeano}

Pasaron varios meses después del triunfo de la fórmula Perón-Quijano, para que el partido que electoralmente posibilitó su triunfo se difundiera en La Pampa de manera formal y organizada. Para ello, se constituyeron núcleos del Partido Laborista en Santa Rosa y en algunas localidades del interior. Con un nivel similar de formalidad, el 5 de mayo de 1946 quedó instalado en Macachín el Centro Laborista "Hipólito Yrigoyen", mientras que en Intendente Alvear, el partido tomó el nombre de "Radical-Laborista". No dejan de llamar la atención las denominaciones de estos centros laboristas, indicadores de los cambios que experimentaba un sector de las filas radicales. En efecto, esta mudanza de adhesiones partidarias se remontaba al golpe del 4 de Junio de 1943. Difícilmente exista una causa única en el giro político al peronismo de radicales con una larga militancia en puestos claves de ese partido como Juan C. Neveu, Pedro Fernández Acevedo, Zenón Mariani, Cornelio Garay Vivas, Benigno Palasciano y José Curci, los que transitaron un camino similar al de FORJA.

Cuando el laborismo se encontraba en pleno desarrollo en La Pampa, el 23 de mayo de 1946, Perón pidió en una alocución radial la supresión de las organizaciones que coincidieron en apoyar su candidatura y la formación de una nueva: el Partido Único de la Revolución Nacional. Mientras que esta

13- Firman la declaración, entre otros, Oscar Gorrachategui, Jorge y Héctor Gonzalo, Carlos Morán, José V. Villarreal y M. Colombato (Archivo Histórico Provincial (AHP), Diario La Arena (LA), $5 / 11 / 1945)$. 
decisión fue rechazada por el laborismo bonaerense liderado por Cipriano Reyes, en La Pampa no se observaron disidencias pues los centros laboristas se habían formado alrededor de la figura exclusiva del presidente. Tan sólo una semana después de iniciado este proceso simultáneo de disolución y centralización de fuerzas, se constituyó la Junta Reorganizadora, luego Junta Territorial del Partido Único de la Revolución Nacional en La Pampa, presidida por el ex conservador Anselmo Palau.

Para arribar a la denominación tradicional, el 15 de enero de 1947 el Consejo Supremo del Partido Único de la Revolución anunció que en lo sucesivo todas las fuerzas contenidas en él se denominarían Partido Peronista. El documento inaugural del peronismo pampeano fue difundido el 19 de marzo de 1947, y su texto completo fue publicado en el primer número del periódico 17 de Octubre. En él se atribuía la organización como partido en el Territorio a una iniciativa del Consejo Superior del peronismo. El núcleo inicial adoptó el nombre de Junta Territorial, y en su documento de presentación se pronunció contra los monopolios cerealeros, un tópico de la realidad económica soslayado en el texto de la Unión Democrática pero que aquí se expresaba como un indicador de las transformaciones que se estaban produciendo en la estructura productiva y en el rol del Estado.

\section{La Revolución del 4 de junio}

En lo inmediato, la primera consecuencia institucional del golpe militar del 4 de junio de 1943 en La Pampa fue la caducidad de todos los presidentes de concejos municipales electivos y su reemplazo por comisionados, una medida que se extendería por más de diez años ${ }^{14}$. De modo que la agitación política que expresan los manifiestos coincide con un período de veda electoral en el único espacio en que los pampeanos ejercían el sufragio: los concejos deliberantes.

El movimiento de los generales Rawson y Ramírez que derrocó al presidente Ramón Castillo, tuvo por pivot discursivo el fraude sistemático y la corrupción de un régimen alumbrado por el golpe militar anterior. El mani-

14- Dicha resolución fue entendida por el entonces Gobernador del Territorio General Duval en un balance de su gestión del año 1943 como una medida tendiente a "... eliminar toda influencia de carácter político o electoral que pudiera perturbar la acción edilicia, sana y constructiva, que este gobierno persigue...". (AHP, Libros Copiadores, Sección Ministerios, 13/12/1943). 
fiesto fundacional del peronismo pampeano recogía esta herencia al hacer mención de los ...13 años de vergüenza, 13 años durante los cuales... se Ilamaron comicios a gigantescas parodias... Trece años, que en su óptica tuvieron su conclusión con el golpe del 4 de junio.

El manifiesto de la Unión Democrática, en cambio, procesaba el 4 de junio como una continuidad del golpe de setiembre de 1930, agravada por el contenido nazi-fascista que le adjudicaba y ensamblaba este proceso con el rosismo ... bárbaro despotismo que hace un siglo ensangrentó la República, todo lo cual tendría por común denominador atentar contra los principios de la Constitución de 1853.

\section{Mercado libre o regulado}

Las nuevas concepciones en materia de intervencionismo estatal, legitimadas a escala mundial por su aplicación en los países centrales, no contaron con un consenso uniforme en torno a los planos económico y social. Los dirigentes de la Unión Industrial Argentina y los grandes productores rurales, por ejemplo, compartieron una parte de las ideas que el golpe militar de 1943 se dispuso a aplicar, pero no tardaron en considerar las nuevas políticas sociales y laborales como una invasión estatal en áreas que el liberalismo dejaba libradas a la esfera del mercado.

Resulta tan reveladora la ausencia de toda referencia a la situación económica en el texto fundacional de la Unión Democrática pampeana, como la cita que de ella se hace en el documento peronista. Sobre este tema, en un mismo día se produjeron en 1947 dos manifestaciones opuestas en La Pampa, reflejando a las fuerzas que en materia de concepciones económicas y sociales buscaban su legitimación en la sociedad argentina. Por un lado, la Junta Territorial del Partido Peronista, en su manifiesto del 19 de marzo, afirmaba que ... en defensa de los agricultores argentinos, el Partido dio por tierra con los grandes consorcios internacionales, y avanzamos para transformar en realidad la justa aspiración de que "la tierra debe ser para quien la trabaja". Frente a este hecho la oligarquía y sus satélites gritan: "Queremos la libre comercialización de las cosechas", que en su lenguaje falaz significa: "Queremos los monopolios"15.

15- El encomillado pertenece a los redactores del documento. Véase el manifiesto completo al final del trabajo. 
Ese mismo 19 de marzo de 1947, se realizó en Santa Rosa un acto organizado por la Asociación Agrícola Ganadera de La Pampa y en esa oportunidad Pedro Berhongaray señalaba "... las circunstancias hacen que hoy más que nunca los productores hayan sentido la necesidad de intensificar su unión a fin de defender sus derechos de libertad, trabajo y libre comercialización de los productos"16.

Durante la Segunda Guerra Mundial y la posguerra la industria resultó más favorecida que la agricultura, desde un Estado que modificó su rol y sus preferencias sectoriales. A través del Instituto Argentino para la Promoción del Intercambio (IAPI), el gobierno peronista encaró una política destinada a alentar el desarrollo de la industria nacional traspasando a este sector las ganancias obtenidas de la comercialización de los productos del campo. Por otra parte, el impacto de diversas medidas tanto cambiarias como arancelarias determinaron, al igual que los efectos del estatuto del peón y el congelamiento del precio de los arrendamientos, una situación adversa para los dueños y productores rurales (Romero 1994).

\section{Trabajadores}

Sin embargo, al cotejar los dos párrafos anteriores surge que la confrontación no estaba limitada a una cuestión técnica sobre dos modelos económicos, sino que adquiría una dimensión política donde los trabajadores sindicalizados bajo plafond estatal cumplieron un rol importante. Así, el manifiesto peronista los calificaba de ... símbolo de la fuerzas de progreso... en su lucha histórica contra la reacción... Una tensión típicamente política, y por otro lado, en el plano específico gremial se solidarizaba ... en su lucha por la realización de sus justas reivindicaciones.

Este doble propósito, paralelo al evitar la difusión de posiciones clasistas o de izquierda en el movimiento obrero, también fue apuntalado en La Pampa por la delegación local de la Secretaría de Trabajo y Previsión. Una de las columnas que conformaron el andamiaje del peronismo en La Pampa, la regional de la Confederación General del Trabajo, se constituyó el 9 de febrero de 1947 en Santa Rosa, en tanto que su primer congreso se concretó en agosto de ese año con la presencia de treinta y cinco sindicatos. Tal con-

16- El subrayado es del original (AHP, $L A, 30 / 3 / 1947)$. 
formación estuvo precedida por notas de alabanzas al entonces Secretario de Trabajo y Previsión Juan D. Perón por parte de varios gremios pampeanos en junio de 1945. Las notas, dirigidas al mismo Perón, fueron publicadas en el Boletín Oficial Informativo de la gobernación de ese mes y año. Una de esas entidades, con el nombre de Sindicato de Reseros de la Zona de Catriló recordaba "esa cordillera de los Andes que hoy constituye para los reseros argentinos EL ESTATUTO DEL PEÓN"17. La idea expuesta era, contrariando el gremialismo anterior, de perfil clasista, confiar toda la acción reivindicativa en el líder y movilizarse sólo en su apoyo.

\section{Provincialización}

Existen, sin embargo y pese a todas las oposiciones descriptas, dos puntos donde ambos movimientos Ilegaron a expresas ideas afines y es justamente en el plano de los derechos políticos: provincialización del Territorio Nacional de la Pampa e incorporación de la mujer en el ámbito de la política.

Los dos movimientos incluyeron en sus discursos fundadores una causa que tenía eco en diversos sectores de la sociedad pampeana y que no era exclusiva de alguna organización política en particular: la causa autonomista ${ }^{18}$. La lucha por la provincialización del Territorio, y con ello el reconocimiento de un estatus jurídico que colocara a La Pampa en un plano de igualdad con el resto de las provincias, se remontaba a principios siglo ${ }^{19}$.

La Unión Democrática describía el status territoriano como una ... transitoria desigualdad política, que no debía impedir que los habitantes de La Pampa se sumaran a una iniciativa nacional concebida en el manifiesto como una ... contienda por la libertad y por la justicia, por el imperio de la Constitución y la soberanía de la ley amenazadas por las fuerzas del nazi-fascismo.

17- Un mes después, en julio de 1945, el Boletín Oficial de la Gobernación publicó la fijación de salarios mínimos para personal no calificado, entre los cuales se contaban los peones, y en 1949 la Comisión Nacional de Trabajo Rural, fijó nuevamente salarios y condiciones de trabajo a acarreadores, arrieros y reseros. La mayúscula de la cita es del original.

18- Esta cuestión ha recibido para el caso de La Pampa un amplio tratamiento. Entre los trabajos más recientes, véase Berhongaray 2000; Asquini 2001 y Etchenique 2001 y 2003.

19- Con antecedentes que se remontan hacia fines del siglo XIX, el 22 de Noviembre de 1907 se formalizó por primera vez una vertiente del movimiento provincialista en La Pampa al crearse el Comité Pro-Autonomía. Desde entonces, surgieron agrupaciones con distintos matices políticos y con proyectos divergentes que demandaron al Gobierno Nacional el cumplimento de la ley 1532 de Creación de los Territorios Nacionales. 
Tanto escritores como periodistas vinculados a la misma, en diversas oportunidades, redactaron memoriales y presentaron mociones en distintos espacios del orden nacional abogando por la pronta provincialización de la Pampa y de otros Territorios Nacionales que presentaban similares condiciones como Río Negro, Misiones y $\mathrm{Chaco}^{20}$. Incluso los candidatos de la Unión Democrática se hicieron eco de estas inquietudes y, al menos una vez, Tamborini declaró que esos cuatro territorios accederían a la autonomía ${ }^{21}$.

Desde el peronismo, el párrafo dedicado en el manifiesto inicial a esta cuestión se inscribía dentro de la línea argumental que ya llevaba treinta años de enunciación ... Los Territorios Nacionales permanecen huérfanos de los elementales derechos políticos de los hombres libres...

La inserción del tema en el documento quizás reflejaba la influencia de viejos provincialistas -mudantes de adhesiones partidarias pero no del "ideal" autonomista- que provenían, en muchos casos, del radicalismo.

El Partido Peronista, en tanto de defensor de los derechos populares, reconocía que los pampeanos habían llegado ya a un alto grado de cultura cívica y que La Pampa debía gozar de los mismos derechos políticos que los demás argentinos. Se prometía en el mismo, aunar esfuerzos para lograr tal aspiración. Finalmente, el reclamo sería concretado en el año 1951. En dicho proceso, las gestiones de Eva Perón, fueron fundamentales para que se sancionara la ley 14.037 que posibilitaba la provincialización de los Territorios Nacionales del Chaco y La Pampa, Ilamada ésta última después Provincia Eva Perón.

\section{Inclusión de la mujer}

La aprobación de la ley de sufragio femenino en 1947, fue el primer paso en el proceso de incorporación de la mujer al mundo de la política institucional. El acceso a la ciudadanía política y a la esfera del gobierno,

20- C. Córdoba Iturburo, Emilio Pettoruti y otros, habían redactado en noviembre de 1945 un memorial bregando por la "desnazificación" del país, y entre otros puntos, por la provincialización de los cuatro territorios nacionales arriba mencionados. También, bajo la influencia de la Unión Democrática local, el escritor José Prado como delegado de la Junta Juvenil de Coordinación Democrática de General Pico, presentó una moción a favor de la provincialización de La Pampa en las Jornadas de la Juventud Argentina realizadas en Buenos Aires en enero de 1946.

21- Esta promesa fue realizada en Resistencia, dos semanas antes de los comicios generales. En esa ocasión, el candidato presidencial precisó que la provincialización de La Pampa estaba incluida en la plataforma. 
representó un incuestionable punto de inflexión en el desarrollo histórico de la vida política argentina. Por primera vez, la mujer era interpelada desde el Estado y se reconocía en tanto ciudadana con derecho a intervenir en el sistema político eligiendo a sus representantes y postulándose como tal para ser elegida (Zink y Di Liscia 2003).

El manifiesto peronista dedicaba algunas líneas a la reivindicación de los derechos cívicos de la mujer ... nada justifica que aún permanezcan cerradas las urnas al pensamiento moderno de la mujer argentina. El párrafo recogía la visión de quienes integraban, promediando el año 1947, el Centro Cívico Femenino de Santa Rosa. Sobre este tema, cabe señalar que de los quince convencionales constituyentes electos el 11 de diciembre de 1951, cuatro eran mujeres y que en esas elecciones, también presidenciales, el voto femenino superó al masculino en apoyo al reelecto Juan D. Perón ${ }^{22}$.

La inclusión de la mujer en el ámbito de las prácticas políticas también estuvo presente en el proyecto de la Unión Democrática. Su manifiesto convocaba el apoyo tanto de los hombres como de las mujeres de todas las clases y condiciones sociales. En 1946, se había formado en Santa Rosa la Agrupación Democrática Femenina. Asimismo, en enero de ese año, había sido inaugurada en la ciudad de General Pico una Escuela de Capacitación Democrática en la que tomaron parte varias mujeres ${ }^{23}$.

\section{Derechos cívicos y derechos sociales, una síntesis}

El impacto del golpe militar del 4 de junio de 1943 en La Pampa produjo cambios en varias dimensiones: clausuró la única vía comicial que tenían los habitantes para ejercer sus restringidos derechos ciudadanos, fue el hecho que condujo a un grupo de dirigentes radicales a iniciar un proceso que los Ilevaría a adherir al peronismo, e institucionalizó un cambio económico de vasto alcance que en La Pampa no se advirtió, aunque sí en el terreno político-social y en la valoración del pasado.

22- Delia Parodi fue la primer mujer pampeana en integrar una cámara legislativa. Asumió como diputada el 25 de mayo de 1952 y en octubre de ese mismo año, luego del fallecimiento de Eva Perón, fue designada presidenta del Consejo Superior del Partido Peronista Femenino, cargo que mantuvo hasta el derrocamiento de Juan D. Perón en 1955.

23- En Santa Rosa se había conformado la Agrupación Democrática Femenina con María Luisa Lordi -quien pronunció un discurso en un acto de la Unión Democrática el 10 de febrero en General Pico-, Cristina Aguilera, Nélida Suárez y Estela Cuadrillero, entre otras. (AHP, LA 19/01/1946). 
La Unión Democrática, a partir de sus experiencias previas, al formarse en diciembre de 1945 construyó en el Territorio un discurso que hacía de las libertades públicas el centro de sus postulados. El lenguaje laborista-peronista, por su parte, incorporó en forma predominante los cambios económicos, laborales y sociales, determinando, con respecto al conglomerado adverso, una disímil conceptualización de la década del 30 y del golpe militar del 4 de junio. La defensa de las instituciones tal como fueron diseñadas por la Constitución de 1853 formó parte del bagaje fundamental de la Unión Democrática, en tanto que el manifiesto peronista hizo hincapié en el derecho a una mayor distribución de los recursos y a la protección social.

La exaltación de los derechos cívicos compartida por ambos movimientos daba cuenta del interés de los territorianos de formar parte de la comunidad política nacional de la cual se hallaban excluidos. Justamente uno de los escasos espacios donde se podía aspirar a ejercer con enormes limitaciones algunos de los derechos cívicos como votar y ser candidato, habían sido clausurados inmediatamente tras el golpe del 4 de Junio de 1943, y no serían restablecidos hasta principios de la década siguiente.

Por su parte, las conquistas sociales y económicas otorgadas por el peronismo tuvieron un impacto real y directo en amplios sectores de la sociedad argentina. En ese plano, el Territorio Nacional de La Pampa vio reconocidos inmediatamente sus derechos sociales, puesto que las leyes que los institucionalizaron al ser de carácter nacional tuvieron aplicación directa en todo el país.

En ese sentido, el peronismo produjo una ampliación real de la ciudadanía en Argentina al otorgar a toda la sociedad una serie de beneficios sociales y laborales largamente demandados. Mas allá de las motivaciones que lo impulsaron, su principal mérito fue, sin duda, redefinir la noción de ciudadanía dentro de un contexto más amplio, esencialmente social (James 1990: 27). Dicha ampliación, devino también de incorporar al Estado a las mujeres y a los pobladores de los Territorios Nacionales que, como a dicho Waldo Ansaldi (1993: 39), eran habitantes pero no ciudadanos.

Por todo lo dicho, consideramos que en el caso de la Pampa, como en el resto de los Territorios Nacionales, la construcción de la ciudadanía en todas sus dimensiones presentó matices singulares que la distinguen de las experiencias vividas por el resto de la sociedad argentina. Aquí, la obtención de los derechos sociales fue un logro previo a la conquista de los derechos políticos. Éstos llegarían recién a partir de 1951, cuando La Pampa y el Chaco fueran los primeros Territorios en ser provincializados. 


\section{Resumen}

A través del análisis de los manifiestos fundacionales de La Junta Pro Unión Democrática y de La Junta Territorial del Partido Peronista en La Pampa, se aborda la relación de adecuación o discordancia entre las cuestiones tratadas en el plano discursivo y las necesidades o situaciones concretas de la sociedad pampeana hacia mediados de los 40 . Se indaga además, acerca de la magnitud real del impacto de las convocatorias plasmadas en esos textos en la población territoriana, teniendo en cuenta la prolongada marginación de estas jurisdicciones respecto de la política nacional y sus alcances con respecto a la construcción de la ciudadanía. En el plano de los derechos sociales, algunos sectores de la sociedad pampeana como los trabajadores, fueron beneficiados en forma real e inmediata con la política peronista, identificándose por tanto con las reivindicaciones sociales y económicas anunciadas en el manifiesto. Sin embargo, desde el punto de vista de los derechos políticos, a diferencia de las provincias y exceptuando el caso de las mujeres, el proceso se hallaba incompleto. Recién en los primeros años de la década del 50, La Pampa gozaría de una ciudadanía plena en la que efectivamente se sentiría parte del Estado nacional.

\section{Palabras claves}

Peronismo - Unión Democrática - Territorios Nacionales - Ciudadanía.

\section{Abstract \\ Reflections upon the analysis of foundation manifestos by Unión De- mocrática and the Peronist Party in La Pampa (1945-1947)}

Through the analysis of foundation manifestos of La Junta Pro Unión Democrática and La Junta Territorial del Partido Peronista in La Pampa we study the relationship of adequacy and difference between the issues posed in the discursive level and the concrete needs and situations of pampean society by the mid 1940's. An analysis is made concerning real dimensions of the impact of interpellations contained in those texts upon the population of the Territory, taking into account the long-term exclusion of such jurisdictions as regards national politics and their reach in the building of citizenship. In the social rights 
level, some sectors of pampean society, like workers, were benefited in a real and immediate way with peronist policies, consequently identifying themselves with social and economic claims announced in the manifesto. However, from the point of view of political rights, differently from the provinces and except for the case of women, the process was incomplete. Not until the first years of the 1950 decade would La Pampa enjoy full citizenship in which it would effectively feel itself as part of the national state.

\section{Key words}

Peronism - Democratic Union - National Territories - Citizenship

\section{Anexo documental}

\section{Manifiesto de la Junta Pro Unión Democrática}

Santa Rosa, 12 de diciembre de 1945

Los vecinos de Santa Rosa, agrupados en la Junta Pro Unión Democrática, han sentido la imperiosa necesidad de definir su posición en el escenario nacional, sumando su esfuerzo al que realiza el pueblo de la Argentina, para lograr el restablecimiento de la forma de gobierno representativa, republicana y federal de la Constitución, que ha sido profundamente alterada desde la Revolución de 1930 y que a partir del 4 de junio de 1943 deriva francamente hacia formas nazi-fascistas, que algunos pocos, afanosamente, se empeñan en entroncar, para satisfacer un nacionalismo feroz, con el bárbaro despotismo que hace un siglo ensangrentó la República, dispersó a sus hijos, retrasó su progreso, quebrantó su unidad y estuvo a un paso de malograr el ideario de Mayo.

Identificados los integrantes de la Junta con el pensamiento rector que ha presidido la formación de la Unión Democrática en el orden nacional y que acaba de ser sobria y bellamente condensado en la proclama leída en la Plaza del Congreso la tarde del 8 de diciembre último, aspiran a promover en esta capital y en toda la extensión de La Pampa, un movimiento de adhesión general a esos principios, que unifique a todos los elementos genuinamente democráticos dispersos en el Territorio, sin distinciones de nacionalidades, razas ni credos políticos o religiosos, para que así nadie quede al margen de esta justa histórica por la libertad y por el derecho, del mismo modo que en el porvenir nadie quedará excluido de las trágicas consecuencias que 
acarrearía la bancarrota de las instituciones fundamentales que derivan de la Constitución del 53, logradas tras largo batallar de nuestros antepasados; Constitución e instituciones que fueron fuente de felicidad, de paz y de orguIlo para los argentinos y defensa y refugio inviolable para los extranjeros.

Recuerda también la Junta a todos vecinos de La Pampa de convicciones democráticas que en esta hora no hay aportes pequeños, ni colaboración que se juzgue despreciable porque está convencida que, aún la sola, pública y sincera afirmación de fe republicana y democrática hecha de un extremo a otro de la Patria con el coraje civil que es la consigna del instante, si fuera apoyada por hombres y mujeres de todas las clases y condiciones sociales, con la decisión franca de traducir el verbo en acción todas las veces y donde así fuere necesario, bastaría para arrasar con todos los intentos de regresión y de despotismo que nos acechan y para restaurar la soberanía de la Ley que se traduce en Libertad, Igualdad y Justicia.

Creen finalmente los hombres de la Junta que La Pampa no puede dejar pasar esta excepcional oportunidad para acreditar que no hay meridiano que la separe del corazón y del cerebro de la nacionalidad, y que su transitoria desigualdad política jamás podrá influir, ni en sus afanes, ni en sus anhelos, ni en sus convicciones cívicas, y que ellos son los mismos que han determinado a sus conciudadanos y a todos los habitantes del resto de la República, identificados con el pasado y ligados a su destino, a librar esta contienda por la libertad y por la justicia, por el imperio de la Constitución y la soberanía de la ley, vasallaje éste que es el único que ennoblece a los hombres y dignifica a los pueblos.

\section{Manifiesto de la Junta Territorial del Partido Peronista}

19 de marzo de 1947

AL PUEBLO DE LA PAMPA

El Consejo Superior del Partido Peronista nos ha confiado la patriótica misión de organizar el Partido en nuestro Territorio.

Al iniciar la tarea reafirmamos una vez más nuestra fe en los altos ideales del Partido, y el convencimiento de que unidos en torno al Líder y su programa de reivindicaciones sociales, políticas y económicas, lograremos ver realizados el ideal de una Patria grande y de un pueblo feliz que cree en su destino histórico.

Surgió el Partido como un grito de liberación del Pueblo, como una reacción contra el desgobierno de la oligarquía, como una reacción contra esa mino- 
ría fraudulenta que pisoteaba la libertad, que afrentaba la vida cívica argentina, que hipotecaba el patrimonio nacional al capitalismo extranjero.

Los trabajadores, símbolo de las fuerzas de progreso, hicieron del partido su bandera, en su lucha histórica contra la reacción.

El Partido ratifica por nuestro intermedio su posición nunca desmentida de total solidaridad con los trabajadores en su lucha por la realización de sus justas reivindicaciones.

En defensa de los agricultores argentinos, el Partido dio por tierra con los grandes consorcios internacionales, y avanzamos para transformar en realidad la justa aspiración de que "la tierra debe ser para quien la trabaja". Frente a este hecho la oligarquía y sus satélites gritan: "Queremos la libre comercialización de las cosechas", que en su lenguaje falaz significa: "Queremos los monopolios".

La lucha contra la oligarquía va tomando otras formas al verse desplazada del gobierno, elementos aún agazapados en la administración nacional, sabotean el programa revolucionario del Partido, tratan de corromper la administración desacreditándolo en cada uno de sus actos.

Esa misma oligarquía, con el apoyo de la prensa venal y reaccionaria, con maniobras arteras, encarece la vida y se enriquece con el hambre del pueblo.

En materia política la acción moralizadora del Partido ha sido tan fecunda como en materia social. 13 años de vergüenza. 13 años durante los cuales se bastardeó la democracia, se subvirtieron los valores y se llamaron comicios a gigantescas parodias. 13 años de ignominia que fueron barridos por la voluntad libremente expresada por el pueblo en los comicios históricos del 24 de febrero de 1946.

Fiel a su programa democrático de renovación política, entendemos que nada justifica que aún permanezcan cerradas las urnas al pensamiento moderno de la mujer argentina.

Los Territorios nacionales permanecen huérfanos de los elementales derechos políticos de los hombres libres. El Partido Peronista, defensor de los derechos populares, entiende que los pampeanos han Ilegado ya a un alto grado de cultura cívica y que La Pampa debe gozar de los mismos derechos políticos que los demás argentinos. En este sentido aunaremos los esfuerzos para transformar estas aspiraciones en una realidad.

La contienda política sostenida con conciencia patriótica y altura cívica, respetando siempre las opiniones adversas e inspirándonos en toda circunstancia en el pensamiento de que una idea se supera sólo con otra idea mejor, 
son las directivas que inspiran a nuestro Partido, y a ellas nos ajustaremos fielmente.

COMPAÑEROS :

EI PARTIDO PERONISTA espera su adhesión sin dobleces para dignificar la vida cívica argentina, la unión en un partido único e indivisible que nos llevará a afianzar la redención de la clase trabajadora y a continuar las reivindicaciones sociales iniciadas y consolidadas por nuestro Líder y Presidente de la Nación: JUAN DOMINGO PERON.

A ingresar al ejército civil de los trabajadores de la Patria. Por el venturoso porvenir de La Pampa, por cuya autonomía lucharemos unidos.

Los hombres que integramos la Junta Territorial del Partido Peronista de La Pampa, nos hacemos un deber y un honor en llamar a nuestras filas a todos los hombres dignos del Territorio.

\section{Bibliografía Citada}

*ALTAMIRANO, Carlos (2002), "Ideologías políticas y debate cívico”, en Nueva Historia Argentina, Tomo VIII, Buenos Aires, Sudamericana, pp. 207255.

*ANSALDI, Waldo (1993), “¿Un caso de nomenclaturas equivocadas?. Los partidos políticos después de la Ley Sáenz Peña, 1916-1930”, en: ANSALDI, W.; Alfredo PUCCIARELLI y José VILLARRUEL (eds.), Argentina en la paz de dos guerras, 1914-1945, Buenos Aires, Biblos, pp. 19-63.

*ARIAS BUCCIARELLI, Mario (2003), "El problema de la construcción de la ciudadanía desde la perspectiva de los territorios nacionales. Un aporte para la discusión", en IX Jornadas Interescuelas y Departamentos de Historia, Córdoba, 24-26 de septiembre.

*ASQUINI, Norberto (2001), El sueño de los bastardos, Santa Rosa, Subsecretaría de Cultura de la Provincia de La Pampa.

*BERHONGARAY, Antonio (2000), La Pampa y su lucha por la autonomía, Buenos Aires, J. C Martínez Ed.

*DIEZ, María A., Vanina HAUSER y Paula DIETRICH (2001), "Las ideas de la prensa acerca de la situación de los territorios nacionales en sus tres primeras décadas. El Congreso de la Prensa Territorial, 1917', en: VIII Jornadas Interescuelas y Departamentos de Historia, Facultad de Humanidades de la Universidad de Salta, Salta,10-12 de septiembre.

*ETCHENIQUE, Jorge (2001), Pampa Central. Movimientos provincialistas y sociedad global. Primera parte (1884-1924), Santa Rosa, Subsecretaría de 
Cultura de la Provincia de La Pampa.

*ETCHENIQUE, Jorge (2003), Pampa Central. Movimientos Provincialistas y sociedad global. Segunda parte (1925-1952), Santa Rosa, Subsecretaría de Cultura de la Provincia de La Pampa.

*FAVARO, Orietta y Mario ARIAS BUCCIARELLI (2002), "Pensar el peronismo desde los Territorios Nacionales. El caso de Neuquén, 1943-1955", en: Cuadernos del Sur-Historia, Bahía Blanca, Universidad Nacional del Sur, $\mathrm{N}^{\circ}$ 30-31, 2001-2003, pp. 85-102.

*GERCHUNOFF, Pablo y Lucas LLACH (1998), El ciclo de la ilusión y el desencanto. Un siglo de políticas económicas argentinas, Buenos Aires, Ariel.

*GUTIERREZ, Leandro y Luis A. ROMERO (1995), Sectores populares, cultura y política, Buenos Aires, Sudamericana.

*JAMES, Daniel (1990), Resistencia e Integración. El Peronismo y la clase trabajadora argentina 1946-1976, Buenos Aires, Sudamericana.

*LEONI, María Silvia (2002), "Los caminos hacia la provincialización", en: Revista Junta de Estudios Históricos del Chaco, Resistencia, Subsecretaría de Cultura de la provincia del Chaco, $\mathrm{N}^{\mathrm{o}} 1$, pp. 59-81.

*LOBATO, Mirta (1997), "El Estado en los años treinta y el avance desigual de los derechos y la ciudadanía", en: Revista Estudios Sociales, Año VII, N ${ }^{\circ}$ 12, Santa Fe, pp. 41-58.

*MAEDER, Ernesto J. A. (2002), "La política sobre los Territorios Nacionales durante la etapa peronista, 1946-1955", en: Revista Junta de Estudios Históricos del Chaco, Subsecretaría de Cultura de la provincia del Chaco, $\mathrm{N}^{\circ} 1$, pp. 137-153.

*PLOTKIN, Mariano (1993), Mañana es San Perón. Propaganda, rituales políticos y educación en el régimen peronista (1946-1955), Buenos Aires, Ariel. *ROMERO, Luis A. (1994), Breve Historia contemporánea de la Argentina, Buenos Aires, FCE.

*RUFFINI, Marta (2003), “Territorios, ciudadanía y luchas por el poder político. Los Consejos Municipales del Territorio Nacional de Río Negro (18861908)", en: IX Jornadas Interescuelas y Departamentos de Historia, Córdoba, 24-26 de septiembre.

*SABATO, Hilda (1994), "Ciudadanía, participación política y la formación de una esfera pública en Buenos Aires, 1850-1880”, en: Entrepasados, Año IV, $\mathrm{N}^{\mathrm{o}}$ 6, pp. 65-86.

*ZINK, Mirta (2000), "Ser mujer, peronista y legisladora en Provincia Eva Perón: una pesada carga", en: Mujeres en escena. Actas de las Quintas Jorna- 
das de Historia de las mujeres y Estudios de Género, UNLPam, Santa Rosa, pp.197-203.

*ZINK, Mirta y María H. DI LISCIA (2003), "Del pueblo a la Legislatura. Voces y relatos de las primeras diputadas", en: Decimosextas Jornadas de Investigación de la Facultad de Ciencias Humanas, UNLPam, Santa Rosa, 1012 de septiembre.

\section{Recibido: 10/02/04}

Aceptado: 20/03/04 